\title{
Does standard post-operative rehabilitation have its place after total knee replacement?
}

\author{
Vavro M, Ziakova E, Gazdikova K, Farkasova D \\ Faculty of Nursing and Professional Health Studies, Slovak Medical University in Bratislava, Bratislava, \\ Slovakia. katarina.gazdikova@szu.sk
}

\begin{abstract}
OBJECTIVE: The pilot study objective was to evaluate the effect of comprehensive post-operative physiotherapeutic treatment on the selected physiotherapeutic parameters as well as patients' quality of life after a total knee joint replacement surgery.

RESULTS: Thirty patients after total knee joint arthroplasty were enrolled into the pilot study. After completing the physiotherapeutic processes, we have observed among the patients who underwent a total knee replacement surgery, a significant increase in muscle strength as with the flexors as well as the extensors $(p=0.001)$, improvement in their range of motion in knee joint flexion, in comparison to its range before treatment $(p=$ $0.001)$, knee pain reduction $(p=0.001)$ and post-operative swelling $(p<0.001)$, respectively. After undergoing the physiotherapeutic procedures, we recorded a statistically significant improvement in the monitored physical components: dressing $(p=0.008)$ and toilet use $(p=0.001)$, transfer from bed to chair $(p=0.008)$, walking on flat surface $(p=0.001)$, climbing stairs $(p=0.001)$. Passing the physiotherapy significantly reduced the degree of dependence of operated patients $(p=0.001)$.

CONCLUSION: Early post-operative physiotherapy treatment positively affects patients' general condition. In addition, it improves muscle strength, range of motion of the operated joint, eliminates post-operative pain and reduces swelling that improves patients' self-sufficiency. Standard physiotherapy nowadays and in the next few years will take a unique place in patients' management after total knee joint replacement (Tab. 5, Ref. 26). Text in PDF www.elis.sk. KEY WORDS: physiotherapy, muscle strength, pain, total joint replacement, knee joint.
\end{abstract}

\section{Introduction}

Osteoarthritis (OA) is a chronic joint disease commonly affecting the joints of the knee, hip, shoulder, spine, ankle and hand. The knee joints are among the earliest and most frequent joints involved in OA. OA patients suffer from considerable functional impairment of the knee joint and severe chronic pain, difficulty performing activities of daily living, sleep problems, and fatigue. They show a range of physical impairments including joint stiffness, muscle weakness, altered proprioception, reduced balance, and gait abnormalities. In addition, psychological impairments such as depression and anxiety are common. The estimated number of patients suffering from knee joint osteoarthritis is $24,000,000$. OA is one of the most common joint diseases seen in the elderly. Its prevalence associates with aging and gender. According to the World Health Organization, OA is commonly regarded as the most important cause of function disability (1-4). Current treatment of OA aims to improve pain and function and enhance quality of life (5).

Surgical treatment - total knee arthroplasty (TKA) is indicated for patients non-responsive to conservative treatment. Its main

Faculty of Nursing and Professional Health Studies, Slovak Medical University in Bratislava, Bratislava, Slovakia

Address for correspondence: K. Gazdikova, MD, PhD, MHA, MPH, Slovak Medical University in Bratislava, Faculty of Nursing and Professional Health Studies, Limbova 12, SK-833 03 Bratislava, Slovakia objective is to eliminate pain, improve physical condition as well as overall quality of life. The expected physiotherapeutic effect is principally an adequate range of motion in the operated knee joint and walking practice $(6,7,8)$.

\section{Objective}

The main objective of the pilot clinical study was to evaluate the impact of early post-operative physiotherapy in patients after total knee joint replacement based upon selected physiotherapeutic parameters. Other objectives were to evaluate its effect on postoperative swelling and patients' self-sufficiency.

\section{Patients and methods}

Thirty patients after total knee replacement surgery, who were hospitalized at the department of physical therapy, balneology and rehabilitation in the period from October 2014 till September 2015, were enrolled into the pilot study. On the first day of hospitalization they went through an entrance medical examination and before the discharge through exit evaluation. The average age of patients was 68.83. The youngest was 53 years old and the oldest 81 years old. Left total knee joint endoprosthesis was implanted in 14 patients, and 16 patients received a right total knee endoprosthesis. A goniometric examination was used for knee joint range of motion detection. To evaluate the muscle strength, we used the muscle test by 
Janda. Thigh circumference was measured by a measuring tape 15 $\mathrm{cm}$ above the patella. Pain was evaluated by visual analogue scale. To judge the self-sufficiency of patients we applied the Barthel index. After implementing the entrance medical examination for patients after a total knee replacement, we developed individual physiotherapeutic program using several methods of kinesiotherapy. The program was adapted to the individual possibilities of active, active- assisted, and isometric exercises. Furthermore, we implemented respiratory and vascular gymnastics exercises with the help of such devices as - fitballs, overballs, cylinders, magic circles, therabands. The patients were practicing two times a day under physiotherapist's supervison - for 30 minutes in the morning and also in the afternoon (totally 60 minutes a day). Besides the classical kineziotherapy with a physiotherapist, patients were exercising with the help of motorized splint for 30 minutes also two times a day. As a complementary therapy to influence the postoperative pain, we applied the available means of physical therapy - local cryotherapy and biolamp application. After completing the post-operative physiotherapeutic program for patients with a total knee joint replacement, we carried out the same examinations as prior to its realization.

\section{Results}

The monitored physiotherapy parameters were evaluated before the start of the physiotherapeutic intervention and after its completion.

Muscle test

After completion of the physiotherapeutic processes, a significant increase in muscle flexor and extensor strength $(p=0.001)$ was observed with patients after a TKA (Tab. 1).

Tab. 1. Effects of post-operative physiotherapy on muscular strength.

\begin{tabular}{lcc}
\hline Name of examination & $\mathrm{Z}$ & $\mathrm{p}$ \\
\hline Muscle test by Janda - knee joint flexion & -5.135 & 0.001 \\
Muscle test by Janda - knee joint extension & -5.135 & 0.001 \\
\hline
\end{tabular}

$\mathrm{Z}$ - value of test statistics, $\mathrm{p}$ - value of statistical significance

\section{Goniometric examination}

A completed physiotherapy treatment resulted in a statistically significant improvement in range of motion in knee joint flexion on average of 25.34 degrees, compared to the range before the treatment $(\mathrm{p}=0.001)$ (Tab. 2).

\section{Pain}

Osteoarthritis is a disease with clinical manifestations of which, apart from the change of momentum is pain, as well. We also focused on the influence of physiotherapeutic methods on the pain itself during our observation. Before the beginning of the physiotherapy, the patients rated their pain with the help of visual analogue scale by number 4 and after the treatment by number 2 $(\mathrm{p}=0.001)($ Tab. 3).

\section{Post-operative swelling}

The post-operative period of total knee joint replacement is accompanied by swelling of the thigh. Therefore, we paid attention to the influence of physiotherapy methods on the swelling itself. After the therapy, we recorded a statistically significant reduction in swelling of a thigh that was expressed by circumference reduction by $1.8 \mathrm{~cm}$ measured $15 \mathrm{~cm}$ above the patella $(50.83 \mathrm{~cm}$ \pm 6.497 vs $6.713 \pm 52.63 \mathrm{~cm}, \mathrm{p}<0.001$ ) (Tab. 4).

\section{Self-sufficiency}

For evaluating the patients' self-sufficiency after a TKA, we used the Barthel Test of daily activities. We evaluated the following physical components from his portfolio - dressing, toilet use, bed to chair transfer, walking on flat surface and climbing stairs. Regarding the other parts - having a bath, eating and drinking, hygiene, fecal and urinary incontinence, we did not examine any statistically significant changes. These served for the overall evaluation of patients' self-sufficiency. After completing the physiotherapy treatment, we recognized statistically significant improvement in the monitored physical areas: dressing $(\mathrm{p}=0.008)$ and toilet use ( $p=0.001)$, transfer from bed to chair $(p=0.008)$, walking on flat surface $(p=0.001)$, climbing stairs $(p=0.001)$ (Tab. 5).

Tab. 2. Physiotherapy treatment effects on the goniometric examination - flexion in the knee joint.

\begin{tabular}{|c|c|c|c|c|c|c|c|}
\hline \multicolumn{3}{|c|}{ Before treatment } & \multicolumn{3}{|c|}{ After treatment } & \multirow[b]{2}{*}{$\mathrm{Z}$} & \multirow[b]{2}{*}{$\mathrm{p}$} \\
\hline Median & SD & $\mathrm{x}$ & Median & $\mathrm{SD}$ & $\mathrm{x}$ & & \\
\hline 40 & 11.090 & 43.33 & 70 & 9.553 & 68.67 & -4.804 & 0.001 \\
\hline
\end{tabular}

$\mathrm{x}$ - arithmetic mean, $\mathrm{Z}$ - value of test statistic, $\mathrm{p}$ - value of statistical significance, $\mathrm{SD}$ - standard deviation

Tab. 3. Post-operative pain by the influence of physiotherapeutic methods.

\begin{tabular}{|c|c|c|c|c|c|c|c|}
\hline \multicolumn{3}{|c|}{ Before treatment } & \multicolumn{3}{|c|}{ After treatment } & \multirow[b]{2}{*}{$\mathrm{Z}$} & \multirow[b]{2}{*}{$\mathrm{p}$} \\
\hline Median & $\mathrm{SD}$ & $\mathrm{x}$ & Median & $\mathrm{SD}$ & $\mathrm{x}$ & & \\
\hline 4.0 & 1.383 & 4.13 & 3.0 & 1.279 & 2.87 & -4.468 & 0.001 \\
\hline
\end{tabular}

$\mathrm{x}$ - arithmetic mean, $\mathrm{Z}$ - value of test statistic, $\mathrm{p}$ - value of statistical significance, $\mathrm{SD}$ - standard deviation

Tab. 4. Influencing the swelling of a thigh by physiotherapeutic methods.

\begin{tabular}{|c|c|c|c|c|c|c|c|}
\hline \multicolumn{3}{|c|}{ Before treatment } & \multicolumn{3}{|c|}{ After treatment } & \multirow[b]{2}{*}{$\mathrm{Z}$} & \multirow[b]{2}{*}{$\mathrm{p}$} \\
\hline Median & $\mathrm{SD}$ & $\mathrm{x}$ & Median & $\mathrm{SD}$ & $\mathrm{x}$ & & \\
\hline 52.00 & 6.713 & 52.63 & 50.50 & 6.497 & 50.83 & -4.783 & 0.001 \\
\hline
\end{tabular}

$\mathrm{x}$ - arithmetic mean, $\mathrm{Z}$ - value of the test statistic, $\mathrm{p}$ - value of statistical significance, $\mathrm{SD}$ - standard deviation 
Tab. 5. Barthel Test physical item influence by physiotherapy intervention.

\begin{tabular}{lcc}
\hline Examination & $\mathrm{Z}$ & $\mathrm{p}$ \\
\hline Dressing & -2.646 & 0.008 \\
Toilet use & -3.464 & 0.001 \\
Transfer from bed to chair & -2.646 & 0.008 \\
Walking on flat surface & -3.945 & 0.001 \\
Climbing stairs & -4.354 & 0.001 \\
The overall outcome of the self-sufficiency assessment & -4.742 & 0.001 \\
Level of dependence & -5.000 & 0.001 \\
\hline Z - value of test statistic, p - value of statistical significance &
\end{tabular}

$\mathrm{Z}$ - value of test statistic, $\mathrm{p}$ - value of statistical significance

\section{Discussion}

Knee replacement surgery is an effective, reliable treatment and is a very common orthopedic intervention withworld-wide rising tendency and is one of the most successful procedures treating patients with later stage of osteoarthritis. The most common indication is osteoarthritis which is among top 10 diseases leading to restrictions during ordinary daily activities in developed countries. Furthermore, they are the cause of invalidity mainly among older people, about $75 \%$ people over 65 years old. Nowadays, there are no precautionary measures or early interventions that would prevent it from happening, more precisely slow down the progression of knee arthritis (9-14). Where conservative treatment fails, surgical intervention takes place - a total knee arthroplasty. According to the Australian National Joint Replacement Registry, joint arthroplasty has a growing tendency. The number has tripled in Europe and there was a $162 \%$ growth visible in America over the past two decades. A joint replacement decreases pain and improves knee function $(9,15)$. Surgical intervention is indicated after a failed conservative treatment. Physiotherapy represents an essential part of the conservative treatment of knee arthritis and is applied as a method of the first choice (16). Physiotherapy is an important part of rehabilitation following TKA and is generally acknowledged. In the post-operative period, the main goal is to achieve an adequate range of motion of the operated joint and practice walking $(17,18$, 8). We have noticed statistically significant muscle flexors and extensors strength of operated joint $(\mathrm{p}<0.001)$. To increase the muscle strength we carried out mainly isometric exercises and exercises against resistance. Isometric exercises help to increase the functional ability of muscles and prevent them from atrophy after a TKA. The role of kinesiotherapy besides improving muscle strength is also positive influencing of the functionality of an operated joint (19).

To ascertain the flexion, we applied a standardized physiotherapeutic - goniometric examination. This kind of examination is an important part of assessing the outcome of total knee arthroplasty. In the monitored group, there was a statistically significant improvement in flexion by 25.34 degrees ( $43.33 \pm 11.090$ vs $68.67 \pm 9.553$, $\mathrm{p}<0.001$ ). The same results were reached by Mizner (2005) who by properly indicating physiotherapy treatment achieved a statistically significant improvement of muscle strength as well as a range of mobility in a knee joint in flexion $(\mathrm{p}<0.001)$. Likewise Ebert (2014), who noticed improvements in flexion in a knee joint with its highest figure of 110 degrees. By the use of the means of physical therapy, particularly negative thermotherapy, it is possible to inhibit pain (22). Pain management is a main determinant of functional recovery after TKA (23). During this treatment, analgesic, anti-oedema and anti-inflammatory effect of cold are mainly used. After the physioterapeutic intervention in our group, there was a visible reduction of pain expressed by the means of visual analogue scale by 1.26 points $(4.13 \pm 1.383$ vs $2.87 \pm 1.279$, $\mathrm{p}<0.001)$. Since musculus quadriceps femoris, in the postoperative period, has a tendency to become weak and edematous, we measured its circumference through the thigh circumference $15 \mathrm{~cm}$ above the patella. The measured values were compared with a healthy lower limb. We statistically analyzed only the values related to the operated limb. For eliminating the post-operative swelling, we used the means of physical therapy, application of cryotherapy mainly for its analgesic and anti-edema effect. Patients were applied cryotheraphy during a day before and after exercising - together four times. When they felt pain in the knee joint, they were informed about the possibility to use a cryo- pack for extra 10 minutes. During the entrance examination we measured the minimum figure of thigh circumference $15 \mathrm{~cm}$, above the patella $36 \mathrm{~cm}$ and maximum of $69 \mathrm{~cm}$. During the therapy, the minimum circumference of $36 \mathrm{~cm}$ and maximum of $68 \mathrm{~cm}$ were measured. By assessing the whole group of patients who underwent total knee joint replacement, we achieved by the means of physiotherapy, a statistically significant reduction of postoperative swelling of a thigh of an operated lower limb by $1.8 \mathrm{~cm}$ in diameter ( $52.63 \pm 50.83 \pm 6.713$ vs $6.497, \mathrm{p}<0.001$ ). For selfsufficiency assessment of patients with a total knee endoprosthesis, various standardized tests were used. The most commonly used is the functional self-sufficiency test, however it was not suitable for our group of patients, since it does not include sufficient number of physical activities that would enable us to assess the self-sufficiency of our patients in their physical activities. Based upon this, we observed as the most appropriate one to be the Barthel test and applied it because it enables assessing physical activities such as dressing, toilet use, transfer from bed to chair, walking on the flat surface, and climbing the stairs. In our study group, after completing the physiotherapeutic treatment we observed statistically significant changes in the physical components of the Barthel Test - dressing $(\mathrm{p}<0.008)$ and toilet use $(\mathrm{p}<0.001)$, transfer from bed to chair ( $p$ $<0.008$ ), walking on flat surface ( $<<0.001$ ), climbing stairs ( $\mathrm{p}<$ 0.001 ). The overall self-sufficiency regarding our group was significantly improved by 13 points ( $82 \pm 95$ vs $12.429 \pm 8.906$, $\mathrm{p}<0.001)$.

Some works pointing to the fact that the hospitalization rate will be reduced for the minimal time during which they bridge the only post-anesthesia complication, and then can continue the treatment at home (24). Later inpatient or outpatient rehabilitation is a discussed question. Some authors recommend only early rehabilitation of patients in hospital with instructions for further home physiotherapy intervention (25). Okoro et al (2016) did not record the difference between the standard physiotherapy treatment in hospitals compared to domestic implemented rehabilitation.

\section{Conclusion}

Rising incidence and prevalence of knee arthritis is accompanied with an increase in total knee arthroplasty. An essential part of 
patients' therapy after a total knee replacement is a physiotherapy treatment which is applied in the pre-operative, early post-operative period as well as after hospital discharge in the form of outpatient therapy. In our pivotal clinical study, we aimed to determine the effectiveness of physiotherapy to improve the health status of patients in the early post-operative period. We observed an increase in muscle strength of the flexors and extensors of the operated knee joint, improved mobility in flexion, reduction of postoperative swelling in thigh area, pain relief and improved self-sufficiency in ordinary daily activities. The results of our study show that physiotherapy interventions implemented at the department of physiotherapy, balneology and medical rehabilitation are the most appropriate. The patient may be repeatedly educated, directed, and in the home environment is pain-free and able to take care of himself, which in case of early released and rehabilitated only at home is not possible.

We can conclude that standard physiotherapy nowadays and in the next few years will have a unique place in the management of patients after total knee joint replacement.

\section{References}

1. Bennel KL, Dobson F, Hinman RS. Exercise in osteoarthritis: Moving from prescription to adherence. Best Pract Res Clin Rheumatol. 2014; 28 (1): 93-117.

2. Igawa T, Katsuhira J. Biomechanical Analysis of Stair Descent in Patients with Knee Osteoarthritis. J Phys Ther Sci 2014; 26 (5): 629-631.

3. Ye J, Cai S, Zhong W, Cai S, Zheng Q. Effects of Tai Chi for patients with knee osteoarthritis: a systematic review. J Phys Ther Sc. 2014; 26 (7): 1133-1137.

4. Qi A, Lin C, Zhou A, Du J, Jia X, Sun L, Zhang G, Zhang L, Liu M. Negative emotions affect postoperative scores for evaluating functional knee recovery and quality of life after total knee replacement. Braz J Med Biol Res 2016; 49 (1): e4616

5. Bennell KL, Hall M, Hinman RS. Osteoarthritis year in review 2015: rehabilitation and outcomes. Osteoarthr Cartilage 2016; 24 (1): 58-70.

6. Han ASY, Nairn L, Harmer AR, Crosbie J, March L, Parker D, Crawford R, Fransen M. Early rehabilitation after total knee replacement surgery: a multicenter, noninferiority, randomized clinical trial comparing a home exercise program with usual outpatient care. Arthr Care Res 2015; 67 (2): 196-202.

7. Tsung-Ching L, Hsing-Kuo W, Jia-Wine Ch, Cheng-Ming Ch, HsiuLing Ch, Chih-Hung $\mathbf{C h}$. Minimally invasive knee arthroplasty with the subvastus approach rapid rehabilitation: a prospective, biomechanical and observational study. J Phys Ther Sci 2013; 25 (5): 557-562.

8. López-Liria R, Padilla-Góngora D, Catalan-Matamoros D, Rocamora-Pérez P, Pérez-de la Cruz S, Fernández-Sánchez M. Home-Based versus Hospital-Based Rehabilitation Program after Total Knee Replacement. BioMed Research International 2015, Article ID 450421, 9 pages.

9. Han AS, Nairn L, Harmer AR, Crosbie J, March L, Parker D, Crawford R, Fransen M. Early rehabilitation after total knee replacement surgery: A multicenter, noninferiority, randomized clinical trial comparing a home exercise program with usual outpatient care. Arthr Care Res 2015; 67 (2): 196-202.

10. Conroy MB, Kwoh CK, Krishnan E, Nevitt MC, Boudreau R, Carbone L, Chen H, Harris T, Newman A. Muscle strength, mass, and quality in older men and women with knee osteoarthritis. Arthr Care Res 2012; 64 (1): 15-21.
11. Labraca NS, Castro-Sánchez AM, Matarán-Peñarrocha GA, ArroyoMorales M, Sánchez-Joya Mdel M, Moreno-Lorenzo C. Benefits of starting rehabilitation within 24 hours of primary total knee arthroplasty:randomized clinical trial. Clin Rehab 2011; 25 (6): 557-566.

12. Levy DL, Martin JR, Watters TS, Jennings JM, Miner TD. Primary total knee arthroplasty in a patient with a chronic extensor mechanism deficiency. Arthroplasty Today 2016; 2 (1): 2-5.

13. Motiffard M, Heidari M, Nemati A. No difference between wound closure in extension or flexion for range of motion following total knee arthroplasty: a randomized clinical trial. Knee Surg Sport Traumatol Arthrosc 2016; 24 (1): 74-78.

14. Hongvilai S, Narkbunnam R, Mow CS. Outpatient total joint arthroplasty- Can it be done safely? A review. Bangkok Med J 2016; 11: 52-56.

15. Noiseux NO, Callaghan JJ, Clark CR, Zimmerman MB, Sluka KA, Rakel BA. Preoperative predictors of pain following total knee arthroplasty. J Arthroplasty 2014; 29 (7): 1383-1387.

16. Ito A, Aoyama T, Tajino J, Nagai M, Yamaguchi S, Iijima H, Zhang X, Akiyama H, Kuroki H. Effects of the Thermal Environment on Articular Chondrocyte Metabolism: A Fundamental Study to Facilitate Establishment of an Effective Thermotherapy for Osteoarthritis. J Jpn Phys Ther Ass 2014; 17 (1): 14-21.

17. Mat Eil Ismail MS, Sharifudin MA, Shokri AA, Ab Rahman S. Preoperative physiotherapy and short-term functional outcomes of primary total knee arthroplasty. Singapore Med J 2016; 57 (3): 138-143.

18. Peter WF, Tilbury C, Verdegaal SH, Onstenk R, Vehmeijer SB, Vermeulen EM, et al. The provision of preoperative and postoperative physical therapy in elderly people with hip and knee osteoarthritis undergoing primary joint replacement surgery. Curr Orthopaed Pract 2016; 27 (2): 173-183.

19. Peter WF, Jansen MJ, Hurkmans EJ, Bloo H, Dekker J, Dilling RG, Hilberding W, Kersten-Smit C, de Rooij M, Veenhof C, Vermeulen HM, de Vos RJ, Schoones JW, Vliet Vlieland TP, Guideline Steering Committee - Hip and Knee Osteoarthritis. Physiotherapy in hip and knee osteoarthritis: development of a practice guideline concerning initial assessment, treatment and evaluation. Acta Rheumatol Port 2011; 36 (3): 268-281.

20. Mizner R, Petterson S, Snyder-Mackler L. Quadriceps strength and the time course of functional recovery after total knee arthroplasty. J Orthop Sport Phys Ther 2005; 35 (7): 424-436.

21. Ebert JR, Munsie C, Joss B. Guidelines for the early restoration of active knee flexion after total knee arthroplasty: implications for rehabilitation and early intervension. Arch Phys Med Rehab 2014; 95 (5): 1135-1140.

22. Tang X, Zhou ZK, Shen B, Kang PD, Yang J, Li J, Pei FX. Total knee arthroplasty in elderly patients with severe Kashin-Beck disease of the knee. Int Orthop 2014; 38 (4): 753-759.

23. Milani P, Castelli P, Sola M, Invernizzi M, Massazza G, Cisari C. Multimodal Analgesia in Total Knee Arthroplasty: A Randomized, DoubleBlind, Controlled Trial on Additional Efficacy of Periarticular Anesthesia. J Arthroplasty 2015; 30 (1): 2038-2042.

24. Husted H, Lunn TH, Troelsen A, Gaarn-Larsen L, Kristensen BB, Kehlet H. Why still in hospital after fast-track hip and knee arthroplasty? Acta Orthopaed 2011; 82 (6): 679-684.

25. Rajan RA, Pack Y, Jackson H, Gillies C, Asirvatham R. No need for outpatient physiotherapy following total knee arthroplasty: a randomized trial of 120 patients. Acta Orthop Scand 2004; 75 (1): 71-73.

26. Okoro T, Whitaker R, Gardner A, Maddison P, Andrew JG, Lemmey A. Does an early home-based progressive resistance training program improve function following total hip replacement? Results of a randomized controlled study. BMC Musculoskel Disord 2016; 17 (1).

Received April 25, 2016. Accepted June 30, 2016. 